\title{
Precocious puberty in Korean girls with and without exposure to endocrine-disrupting chemicals in toy slime: a comparative analysis
}

Mi Seon Lee ${ }^{1}$ Gi Min Lee ${ }^{1}$ Cheol Woo Ko ${ }^{1}$ and Jung Eun Moon ${ }^{1,2^{*}}$

\begin{abstract}
Background: Toy slime is popular in Korea, and in parallel, pre-pubertal girls visit hospitals for early pubertal signs. Thus far, numerous studies have investigated the association of endocrine-disrupting chemicals (EDCs) with precocious puberty (PP). However, there is a lack of studies on the clinical manifestations and sex hormones. We aimed to investigate early pubertal development in Korean girls with or without a history of toy slime exposure and determine changes in bone age, Tanner stage, and sex hormones.

Methods: In this study, 140 girls underwent stimulation tests at Kyungpook National University Children's Hospital Endocrinology Department, during January 2018 and December 2020. Patients were divided into two groups for gonadotropin-releasing hormone $(\mathrm{GnRH})$ stimulation test and frequency of exposure to toy slime (EDCs). GnRH stimulation test was conducted after an intravenous injection of $100 \mu \mathrm{g}$ of luteinizing hormone-releasing hormone. Slime exposure was defined as Slime $\geq 3$ times/week for $\geq 3$ months.

Results: History of slime exposure was found in 14 of 58 and 65 of 82 patients in the central PP (CPP) and non-CPP groups, respectively. Slime-exposed patients had advanced bone age, although their Tanner stage was low. Patients with a history of toy slime exposure were 5.5 times more likely to be diagnosed with non-CPP than patients without slime exposure $(p<0.05)$.
\end{abstract}

Conclusions: Exposure to toy slime in prepubertal girls may be associated with rapid clinical advancement of pubertal development and bone age, and the patients appear more likely to be diagnosed with non-CPP.

Keywords: Endocrine disruptors, GnRHa treatment, Precocious puberty, Sex hormones

\footnotetext{
* Correspondence: subuya@daum.net

'Department of Pediatrics, School of Medicine, Kyungpook National

University, Kyungpook National University Hospital, Daegu, Republic of Korea

${ }^{2}$ Department of Pediatric Endocrinology, Kyungpook National University

Children's Hospital, 807, Hoguk-ro, Buk-gu, 41404 Daegu, Republic of Korea
}

(c) The Author(s). 2021 Open Access This article is licensed under a Creative Commons Attribution 4.0 International License, which permits use, sharing, adaptation, distribution and reproduction in any medium or format, as long as you give appropriate credit to the original author(s) and the source, provide a link to the Creative Commons licence, and indicate if changes were made. The images or other third party material in this article are included in the article's Creative Commons licence, unless indicated otherwise in a credit line to the material. If material is not included in the article's Creative Commons licence and your intended use is not permitted by statutory regulation or exceeds the permitted use, you will need to obtain permission directly from the copyright holder. To view a copy of this licence, visit http://creativecommons.org/licenses/by/4.0/ The Creative Commons Public Domain Dedication waiver (http://creativecommons.org/publicdomain/zero/1.0/) applies to the data made available in this article, unless otherwise stated in a credit line to the data. 


\section{Background}

Precocious puberty (PP) in girls is defined as a condition wherein the first pubertal sign occurs before the age of 8 years [1]. It is categorized into central PP (CPP), peripheral PP (PPP), and benign pubertal variants. In the gonadotropin-releasing hormone $(\mathrm{GnRH})$ stimulation test, CPP is GnRH-dependent, while PPP is GnRH-independent [2]. The causes of PP vary, including idiopathic, central nervous system tumors, and ovarian tumors [3, 4]. Recently, the presence of endocrine-disrupting chemicals (EDCs) in the environment has received much attention as a factor that disturbs the onset and progression of pubertal development [5]. EDCs are found in many products, ranging from plastic products to metal food cans, cosmetics, and toys. The EDCs associated with PP are bisphenols (BPA), phthalates, and pyrethroids. Most studies on EDCs and PP conducted thus far have focused on analyzing the detected levels of EDCs [6]. In addition, a greater number of studies have investigated the detected levels and specific types of EDCs in patients previously diagnosed with CPP and compared the data with those in control subjects [7-10]. Thus, there is a lack of studies on EDC exposure frequency in patients with $\mathrm{PP}$, its clinical manifestations, and effects on hormone test data. Since the past few years in Korea, a toy known as "toy Slime" has become highly popular. The Korean Agency for Technology and Standards of the Ministry of Trade, Industry, and Energy conducted an investigation of harmful substances present in the commercially available toy Slime in Korea and reported that the level of DEHP (di-2-ethylhexyl phthalate) in several slime toys exceeded the safety limit [11]. This study therefore investigated the history of toy slime exposure (history of exposure to EDCs) in patients who visited the hospital due to early pubertal development. This study also determined the changes in bone age (BA), Tanner stage, and sex hormones including GnRH stimulation test results.

\section{Methods}

\section{Ethical approval}

This study was approved by the Institutional Review Board of Kyungpook National University Chilgok Hospital, Daegu, Korea (approval number: 2020-04-029). As this was a retrospective study, the need for obtaining informed consent from patients was waived by the Institutional Review Board.

\section{Subjects}

In this retrospective comparative analysis, 140 girls who underwent GnRH stimulation tests at Kyungpook National University Children's Hospital Endocrinology
Department due to PP between January 2018 and December 2020 were included. Using the classic definition, PP was defined as the first pubertal sign that occurs before the age of 8 years in girls [12]. GnRH stimulation tests were performed in all the patients. For analyses, study patients were divided into groups according to the $\mathrm{GnRH}$ stimulation test results and history of exposure to toy Slime (EDCs). The GnRH stimulation test was conducted between 09:00 and 10:00. After administering an intravenous injection of $100 \mu \mathrm{g}$ of luteinizing hormone (LH)-releasing hormone (LHRH; Gonadorelin), blood samples were collected at $0,15,30,45$, and 60 min. Peak LH concentration of $\geq 5 \mathrm{mIU} / \mathrm{L}$ was defined as being representative of the pubertal pattern [13, 14]. History of exposure to slime was defined as exposure to Slime $\geq 3$ times/week for $\geq 3$ months at the time of $\mathrm{GnRH}$ stimulation tests. Age, BA, BA chronological age (CA), body mass index (BMI; z-score), Tanner stage, basal LH level, folliclestimulating hormone (FSH) level, DHEA-s level, and $\mathrm{GnRH}$ stimulation test results were retrospectively analyzed for each subject. BA was measured by two experts using the method of Pyle and Glenlich, and the mean value was obtained [15]. Pubertal development was evaluated by two endocrinologists based on Tanner's criteria.

\section{Statistical analyses}

Statistical analyses were performed using IBM SPSS, version 23.0 (IBM Co., Armonk, NY, USA). The twosample t-test was used to compare baseline characteristics between the two groups, and the chi-square test was used to evaluate the association between the history of exposure to slime (EDCs) and GnRH stimulation test results. Statistical significance was set at $p<0.05$.

\section{Results}

The mean age of the 140 prepubertal girls who visited the hospital for PP was $7.04 \pm 0.98$ years. The mean Tanner stage was $3.03 \pm 0.68$, and the mean BMI was $18.19 \pm 2.99 \mathrm{~kg} / \mathrm{m}^{2}$ (BMI for age $\mathrm{z}$-score was $1.01 \pm 1.50$ ).

In total, 140 patients were categorized depending on the GnRH stimulation test results for a comparative analysis: 58 patients $(41.4 \%)$ were included in the $\mathrm{GnRH}(+)$ group and 82 patients $(58.6 \%)$ in the $\mathrm{GnRH}(-)$ group. The two groups showed no significant differences in CA or BA-CA and height SDS. BMI was significantly lower in the GnRH (-) group. The Tanner stage was significantly higher in the GnRH (+) group than in the GnRH (-) group ( $3.33 \pm 0.75$ vs. $2.83 \pm 0.56, P<0.05)$. Although the two groups showed no significant difference in basal LH levels, basal FSH and the peak LH/FSH ratio were significantly higher in the $\mathrm{GnRH}(+)$ group. A history of slime exposure was significantly more common (79.2\%) in the GnRH (-) group than in the other group $(P<$ 0.05) (Table 1). 
Table 1 Clinical and laboratory characteristics of the study groups based on GnRH stimulation test results

\begin{tabular}{lllr}
\hline Characteristic & GnRH(+) $(\boldsymbol{n = 5 8 )}$ & GnRH(-) $(\boldsymbol{n}=\mathbf{8 2})$ & $\boldsymbol{p}$ value \\
\hline CA(yr) & $6.99 \pm 0.82$ & $7.08 \pm 1.09$ & 0.600 \\
BA-CA(yr) & $0.55 \pm 1.22$ & $0.95 \pm 1.12$ & 0.053 \\
Tanner stage & $3.33 \pm 0.75$ & $2.83 \pm 0.56$ & $<0.05^{*}$ \\
Height SDS & $0.90 \pm 1.54$ & $1.28 \pm 1.34$ & 0.120 \\
BMl Z-score & $0.50 \pm 1.24$ & $1.37 \pm 1.58$ & $<0.05^{*}$ \\
Basal LH(mIU/mL) & $0.80 \pm 3.47$ & $0.08 \pm 0.10$ & 0.065 \\
Peak LH(mIU/mL) & $9.63 \pm 9.25$ & $2.38 \pm 1.17$ & $<0.05^{*}$ \\
Basal FSH(mIU/mL) & $3.02 \pm 1.60$ & $1.77 \pm 1.25$ & $<0.05^{*}$ \\
Peak FSH(mIU/mL) & $21.89 \pm 7.69$ & $14.32 \pm 6.75$ & $<0.05^{*}$ \\
Peak LH/Peak FSH & $0.50 \pm 0.48$ & $0.19 \pm 0.11$ & $<0.05^{*}$ \\
Slime (EDCs) exposure(N, \%) & $14(24.1 \%)$ & $65(79.2 \%)$ & $<0.05^{*}$ \\
\hline
\end{tabular}

GNRH gonadotropin-releasing hormone, CA chronological age, yr years, BA Bone age, BMI body mass index, LH Luteinizing hormone, FSH Follicle-stimulating hormone, $N$ number, $E D C s$ endocrine-disrupting chemicals

${ }^{*} P$ value $<0.05$

A total of 140 patients were categorized depending on their toy slime (EDC) exposure history for a comparative analysis: 79 patients were included in the Slime $(+)$ group and 61 patients in the Slime (-) group. BA-CA was significantly higher in the Slime $(+)$ group than in the other group $(0.92 \pm 1.3$ vs. $0.59 \pm 1.15, P<0.05)$. Height SDS was significantly higher in the Slime $(+)$ group than in the other group $(1.37 \pm 1.29$ vs. $0.80 \pm$ $1.55, P<0.05)$. The Tanner stage was slightly lower $(2.92 \pm 0.64$ vs. $3.18 \pm 0.74, p<0.05)$ in the Slime $(+)$ group than in the other group. BMI showed no significant intergroup differences. There was no significant difference in the basal LH level between the two groups, whereas basal FSH and the peak LH/FSH ratio were significantly lower in the Slime (-) group than in the other group. The number of patients with a positive result in the GnRH stimulation test was $14(17.7 \%)$ in the Slime (+) group and $44(72.1 \%)$ in the Slime (-) group, indicating that it was more frequent in the Slime $(+)$ group than in the Slime (-) group (Table 2). The results of the chi-square test that compared the Slime $(-)$ and $(+)$ groups predicted that the likelihood of a diagnosis of non-CPP was 5.55 times higher in patients with toy Slime exposure than in those without the exposure $(P<$ 0.001) (Fig. 1).

Among the 140 patients, 82 patients with a negative result in the GnRH stimulation test (non-CPP patients) were divided according to their toy slime exposure history for a comparative analysis. The number of non-CPP patients in the Slime (+) group was 65/82 (79.2\%), whereas the number of non-CPP patients in the Slime (-) group was 17/82 (20.8\%). CA, BA-CA, Height SDS, and Tanner stage showed no significant intergroup differences. The basal LH and peak LH levels showed no significant difference, while the peak LH/FSH ratio was significantly lower in the Slime $(+)$ group than in the other group $(0.17 \pm 0.11$ vs. $0.24 \pm 0.13, \quad p<0.05)$ (Table 3).

\section{Discussion}

This study reports the results of a comparative analysis of clinical and $\mathrm{GnRH}$ stimulation test results based on the toy Slime (EDCs) exposure history of patients visiting the hospital due to PP. The frequency of non-CPP diagnosis was higher in the Slime $(+)$ group that showed advanced BA-CA. Moreover, the Tanner stage was lower in the Slime $(+)$ group, with a significantly lower peak LH/FSH in the GnRH stimulation test.

Previous studies regarding exposure to EDCs, including phthalate and PP, have reported controversial results. The study by Chou in 2009 [7] and that by Wolff in 2010 [16] reported a high frequency of phthalate

Table 2 Differences in clinical and laboratory characteristics according to toy slime (EDC) exposure

\begin{tabular}{lllr}
\hline Characteristic & Slime $(+)(\boldsymbol{n}=\mathbf{7 9})$ & Slime $(-)(=61)$ & $\boldsymbol{p}$ value \\
\hline BA-CA(yr) & $0.92 \pm 1.30$ & $0.59 \pm 1.15$ & $<0.05^{*}$ \\
Tanner stage & $2.92 \pm 0.64$ & $3.18 \pm 0.74$ & $<0.05^{*}$ \\
Height SDS & $1.37 \pm 1.29$ & $0.80 \pm 1.55$ & $<0.05^{*}$ \\
BMl z-score & $1.18 \pm 1.54$ & $0.79 \pm 1.45$ & 0.131 \\
Basal LH(mIU/mL) & $0.43 \pm 2.90$ & $0.31 \pm 0.89$ & 0.733 \\
Peak LH $(\mathrm{mIU} / \mathrm{mL})$ & $3.70 \pm 5.23$ & $7.80 \pm 8.17$ & $<0.05^{*}$ \\
Basal FSH(mIU/mL) & $1.96 \pm 1.44$ & $2.71 \pm 1.54$ & $<0.05^{*}$ \\
Peak FSH(mIU/mL) & $15.79 \pm 7.27$ & $20.06 \pm 8.47$ & $<0.05^{*}$ \\
Peak LH/Peak FSH & $0.25 \pm 0.26$ & $0.42 \pm 0.43$ & $<0.05^{*}$ \\
GnRH positive $(\mathrm{N}, \%)$ & $14(17.7 \%)$ & $44(72.1 \%)$ & $<0.05^{*}$ \\
\hline
\end{tabular}

$E D C s$ endocrine-disrupting chemicals, $C A$ chronological age, yr years, $B A$ Bone age, $B M I$ body mass index, $L H$ Luteinizing hormone, FSH Follicle-stimulating hormone, $N$ number, GNRH gonadotropin-releasing hormone, GnRH(+) Percentage of positive of $\mathrm{GnRH}$ stimulation test

${ }^{*} P$ value $<0.05$ 


\section{$\mathrm{GnRH}(+)$}

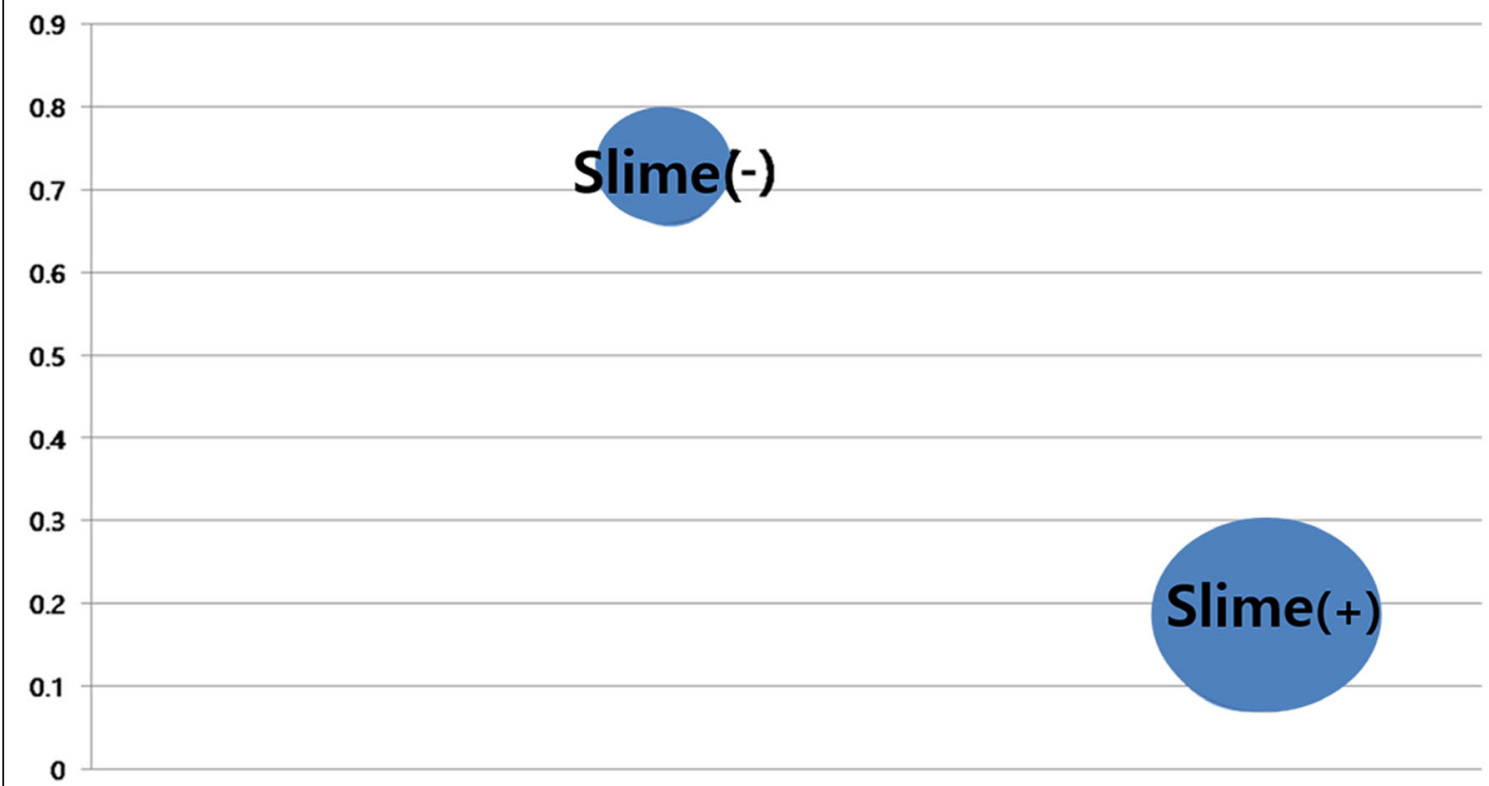

- $\mathrm{GnRH}(+)$

Fig. 1 Association between history of exposure to toy slime (EDCs) and GnRH stimulation test results. The possibility of a diagnosis of non-CPP was 5.55 times higher in patients with toy Slime exposure than in those without the exposure $(P<0.001)$. Results of the chi-square test for the comparison between the two groups. EDC, endocrine-disrupting chemical; GnRH, gonadotropin-releasing hormone

detection in CPP patients, whereas the study by Buttke in 2012 and that by Frederiken in 2012 reported no significant difference $[17,18]$. As such, the results of studies regarding EDC and PP have been controversial. In this study, patients with pubertal signs and advanced BA were examined; patients with a negative result in the $\mathrm{GnRH}$ stimulation test accounted for 82 out of 140 $(58.5 \%)$, indicating that a high proportion of those with PP had non-CPP. For the 82 patients diagnosed with

Table 3 Differences in clinical and laboratory characteristics in the non-CPP group according to toy slime exposure

\begin{tabular}{lccc}
\hline Characteristic & Slime $(+)(\boldsymbol{n}=\mathbf{6 5})$ & Slime $(-)(=17)$ & $\boldsymbol{p}$ value \\
\hline CA(yr) & $7.03 \pm 1.02$ & $7.27 \pm 1.31$ & 0.433 \\
BA-CA(yr) & $0.96 \pm 1.13$ & $0.62 \pm 1.02$ & 0.285 \\
Tanner stage & $2.83 \pm 0.60$ & $2.82 \pm 0.39$ & 0.963 \\
Height SDS & $1.41 \pm 1.25$ & $0.79 \pm 1.58$ & 0.092 \\
BMl z-score & $1.64 \pm 2.06$ & $1.89 \pm 1.86$ & 0.624 \\
Basal LH(mIU/mL) & $0.087 \pm 0.01$ & $0.070 \pm 0.002$ & 0.569 \\
Peak LH $(\mathrm{mlU} / \mathrm{mL})$ & $2.26 \pm 1.11$ & $2.83 \pm 1.29$ & 0.073 \\
Basal FSH(mIU/mL) & $1.83 \pm 1.32$ & $1.55 \pm 0.92$ & 0.320 \\
Peak FSH(mIU/mL) & $14.59 \pm 9.73$ & $13.28 \pm 6.94$ & 0.721 \\
Peak LH/Peak FSH & $0.17 \pm 0.11$ & $0.24 \pm 0.13$ & $0.027^{*}$ \\
\hline
\end{tabular}

$C A$ chronological age, $y r$ years, $B A$ Bone age, $B M I$ body mass index, $L H$ Luteinizing hormone, FSH Follicle-stimulating hormone, $N$ number

${ }^{*} P$ value $<0.05$
non-CPP, a slime (EDC) exposure history was found in $79.2 \%$ of patients. In an analysis based on lime exposure history, the frequency of CPP diagnosis in patients with a history of slime exposure among those visiting the hospital due to PP was relatively low at $17.7 \%$, while the frequency of CPP diagnosis in patients without a slime exposure history was high at $72.1 \%$. Thus, a patient with a history of slime exposure is more likely to be diagnosed with non-CPP rather than with $\mathrm{CPP}$, which suggests that a slime exposure history may lead to nonCPP.

BA advancement is commonly observed in patients with PP. It is well known that sex hormones are closely associated with the maturation of the epiphyseal plate [19]. In the study by Buluş et al., the EDC detection frequency was high in CPP patients, with a significantly high level of bone advancement. In this study, the frequency of non-CPP diagnosis was high in patients with a history of slime exposure, who simultaneously showed an advancement of BA [20]. It is presumed that exposure to EDCs could have promoted the advancement of $\mathrm{BA}$, as previously reported. Buluş et al. reported no change in basal hormone levels when phthalate detection was performed in patients with CPP and PPP [20]. Similarly, in this study, no notable intergroup difference was found in the basal hormone levels. However, in patients in the GnRH (-) group with a history of slime exposure, the peak LH/FSH ratio in the GnRH stimulation 
test was significantly lower. It is well known that EDCs influence ovarian folliculogenesis and ovarian function in adults [21]. Hannon et al. reported that phthalate exposure in mice accelerates primordial follicle recruitment [22, 23]. This suggests that EDC exposure in prepubertal girls further promoted the advancement of $\mathrm{BA}$, which may be due to the activation of FSH rather than LH, leading to the progression to non-CPP. Thus, the findings of this study indicate a high probability of the development of non-CPP in patients with a history of slime exposure, and the possibility of PP induced by folliculogenesis due to FSH activation. In the future, additional studies should be conducted regarding the disturbance and association between slime and folliculogenesis in pediatric patients.

Furthermore, from a clinical perspective, the association between exposure to slime and PP is clear; however, the challenge lies in screening for indications that require $\mathrm{GnRH}$ agonist treatment. In this study, the correlation between slime exposure and $\mathrm{GnRH}$ stimulation test results was determined using the chi-square test. The probability of a patient with a history of Slime exposure diagnosed with CPP was 5.55 times lower, a statistically significant difference. This indicates a high probability of a negative result in the GnRH stimulation test for patients with a slime exposure history when they visit the hospital due to PP. In addition, while BA advancement and Height SDS were significantly higher in patients with a slime exposure history, the Tanner stage was low, and there was no difference in BMI.

The investigation in this study focused on the history of exposure to toy slime (EDC exposure history), while the limitation is that the specific type of EDC in each slime product and the detected amount of EDC were not analyzed. Further studies should examine the EDCs detected in the urine and blood of patients with a slime exposure history and the EDCs detected in the slime product itself.

\section{Conclusions}

Exposure to toy slime in prepubertal girls may be associated with rapid clinical advancement of pubertal development and bone age, and the patients appear more likely to be diagnosed with non-CPP.

\section{Acknowledgements}

Not applicable.

\section{Authors' contributions}

MSL was responsible for the acquisition of clinical information and writing and for reviewing the manuscript and figures. GML and CWG collected the clinical data. MSL and JEM analyzed and interpreted the data and drafted the manuscript. All authors read and approved the final manuscript.

\section{Funding}

Not applicable.

\section{Availability of data and materials}

The datasets used and analyzed during the current study are available from the corresponding author upon reasonable request.

\section{Declarations}

\section{Ethics approval and consent to participate}

This study was approved by the Institutional Review Board of Kyungpook National University Chilgok Hospital, Daegu, Korea (approval number: 202004-029). All methods were performed in accordance with relevant guidelines and regulations.

As this was a retrospective study, the need for obtaining informed consent from patients was waived by the Institutional Review Board of Kyungpook National University Chilgok Hospital, Daegu, Korea (approval number: 202004-029).

\section{Consent for publication}

Not applicable.

\section{Competing interests}

The authors declare that they have no competing interests.

Received: 4 March 2021 Accepted: 7 September 2021

Published online: 18 September 2021

\section{References}

1. Boepple PA, Crowley WF Jr. Precocious puberty. In: Adashi EY, Rock JA, Rosenwaks Z, editors. Reproductive endocrinology, surgery, and technology, vol. 1. Philadelphia: Lippincott-Raven; 1996. p. 989.

2. Harrington J, Palmert MR, Hamilton J. Use of local data to enhance uptake of published recommendations: an example from the diagnostic evaluation of precocious puberty. Arch Dis Child. 2014;99(1):15-20.

3. Biro FM, Khoury P, Morrison JA. Influence of obesity on timing of puberty. Int J Androl. 2006;29(1):272-7 discussion 286.

4. Dunger DB, Ahmed ML, Ong KK. Early and late weight gain and the timing of puberty. Mol Cell Endocrinol. 2006;254-255:140-5.

5. Buck Louis GM, Gray LE Jr, Marcus M, Ojeda SR, Pescovitz OH, Witchel SF, et al. Environmental factors and puberty timing: expert panel research needs. Pediatrics. 2008;121(Suppl 3):S192-207.

6. Lee JE, Jung HW, Lee YJ, Lee YA. Early-life exposure to endocrine-disrupting chemicals and pubertal development in girls. Ann Pediatr Endocrinol Metab. 2019;24:78-91.

7. Chou YY, Huang PC, Lee CC, Wu MH, Lin SJ. Phthalate exposure in girls during early puberty. J Pediatr Endocrinol Metab. 2009;22:69-77.

8. Colón I, Caro D, Bourdony CJ, Rosario O. Identification of phthalate esters in the serum of young Puerto Rican girls with premature breast development. Environ Health Perspect. 2000;108:895-900.

9. Qiao L, Zheng L, Cai D. Study on the di-n-butyl phthalate and di-2ethylhexyl phthalate level of girl serum related with precocious puberty in Shanghai. Wei Sheng Yan Jiu. 2007;36:93-5.

10. Lee SW, Lee WJ, Chae HW, Lee EB, Kim JH, Kim DH, et al. Determination of serum di-(2-ethylhexyl) phthalate and bisphenol A level in children with idiopathic central precocious puberty. J Korean Soc Pediatr Endocrinol. 2009;14:154-62.

11. Tae-hee L. Slime-based toys recalled by Govt over hazardous substances; 2018. http://www.koreaherald.com/view.php?ud=20181220000766. Accessed 20 Dec 2018.

12. Berberoğlu M. Precocious puberty and normal variant puberty: definition, etiology, diagnosis and current management. J Clin Res Pediatr Endocrinol. 2009;1(4):164-74.

13. Resende EAMR, Lara BHJ, Reis JD, Ferreira BP, Pereira GA, Borges MF. Assessment of basal and gonadotropin-releasing hormone-stimulated gonadotropins by immunochemiluminometric and immunofluorometric assays in normal children. J Clin Endocrinol Metab. 2007;92(4):1424-9.

14. Neely EK, Hintz RL, Wilson DM, Lee PA, Gautier T, Argente J, et al. Normal ranges for immunochemiluminometric gonadotropin assays. J Pediatr. 1995; 127(1):40-6.

15. Greulich WW, Pyle SI. Radiographic atlas of skeletal development of the hand and wrist. 2nd ed. Stanford: Stanford University Press; 1959.

16. Wolff MS, Teitelbaum SL, Pinney SM, Windham G, Liao L, Biro F, et al. Investigation of relationships between urinary biomarkers of 
phytoestrogens, phthalates, and phenols and pubertal stages in girls. Environ Health Perspect. 2010;118:1039-46.

17. Buttke DE, Sircar K, Martin C. Exposures to endocrine-disrupting chemicals and age of menarche in adolescent girls in NHANES (2003-2008). Environ Health Perspect. 2012;120:1613-8.

18. Frederiksen H, Sørensen K, Mouritsen A, Aksglaede L, Hagen CP, Petersen $\mathrm{JH}$, et al. High urinary phthalate concentration associated with delayed pubarche in girls. Int J Androl. 2012;35:216-26.

19. Martin DD, Wit JM, Hochberg Z, Sävendahl L, van Rijn RR, Fricke O, et al. The use of bone age in clinical practice-part 1. Horm Res Paediatr. 2011: 76(1):1-9.

20. Buluş AD, Aşci A, Erkekoglu P, Balci A, Andiran N, Koçer-Gümüşel B. The evaluation of possible role of endocrine disruptors in central and peripheral precocious puberty. Toxicol Mech Methods. 2016;26(7):493-500.

21. Patel S, Zhou C, Rattan S, Flaws JA. Effects of endocrine-disrupting chemicals on the ovary. Biol Reprod. 2015;93(1):20.

22. Hannon PR, Peretz J, Flaws JA. Daily exposure to di(2-ethylhexyl) phthalate alters estrous cyclicity and accelerates primordial follicle recruitment potentially via dysregulation of the phosphatidylinositol 3-kinase signaling pathway in adult mice. Biol Reprod. 2014;90:136.

23. Hannon PR, Brannick KE, Wang W, Flaws JA. Mono(2-ethylhexyl) phthalate accelerates early folliculogenesis and inhibits steroidogenesis in cultured mouse whole ovaries and antral follicles. Biol Reprod. 2015;92(5):120.

\section{Publisher's Note}

Springer Nature remains neutral with regard to jurisdictional claims in published maps and institutional affiliations.

Ready to submit your research? Choose BMC and benefit from:

- fast, convenient online submission

- thorough peer review by experienced researchers in your field

- rapid publication on acceptance

- support for research data, including large and complex data types

- gold Open Access which fosters wider collaboration and increased citations

- maximum visibility for your research: over $100 \mathrm{M}$ website views per year

At BMC, research is always in progress.

Learn more biomedcentral.com/submissions 